\title{
Lung cancer patients harboring epidermal growth factor receptor mutation among those infected by human immunodeficiency virus
}

This article was published in the following Dove Press journal:

OncoTargets and Therapy

31 December 2014

Number of times this article has been viewed

\author{
Yusuke Okuma' \\ Yukio Hosomi' \\ Akifumi Imamura ${ }^{2}$ \\ 'Department of Thoracic Oncology \\ and Respiratory Medicine, Tokyo \\ Metropolitan Cancer and Infectious \\ diseases Center Komagome \\ Hospital, Tokyo, Japan; ' $D e p a r t m e n t$ \\ of Infectious Disease, Tokyo \\ Metropolitan Cancer and Infectious \\ diseases Center Komagome Hospital, \\ Tokyo, Japan
}

\begin{abstract}
With the advent of antiretroviral therapy, lung cancer has become a crucial health problem among individuals living with human immunodeficiency virus (HIV). In East Asian populations, the frequency of lung cancer patients harboring epidermal growth factor receptor $(E G F R)$ mutations is greater than in other populations. Herein, we present two cases of advanced non-small cell lung cancer with EGFR mutations in patients treated with EGFR-tyrosine kinase inhibitors. Both patients were male, 67 and 59 years of age, with known HIV infection and immunologically stable disease with antiretroviral therapy. Case 1 was treated with erlotinib for recurrent adenocarcinoma metastasizing to the liver and brain harboring EGFR mutation in exon 21 L858R. The duration of treatment efficacy was 9.7 months. Case 2 had an EGFR mutation exon 19 in-frame deletion with bone metastasis and was treated with gefitinib for 22.1 months in combination with antiretroviral therapy. These advanced lung cancer patients living with HIV with EGFR mutations demonstrate the promising effectiveness and safety of EGFR-tyrosine kinase inhibitors concomitant with antiretroviral therapy for an extended period.
\end{abstract}

Keywords: non-small cell lung cancer, human immunodeficiency virus, antiretroviral therapy, epidermal growth factor receptor mutation, non-AIDS-defining cancers

\section{Introduction}

Patients living with human immunodeficiency virus (HIV) survive longer following the advent of antiretroviral therapy. ${ }^{1,2}$ Consequently, an increased incidence of nonAIDS-defining cancers is recognized as a crucial factor among individuals living with HIV. ${ }^{3}$ Today, roughly one third of HIV-infected patients die of malignancies, and lung cancer is a leading cause of death among non-AIDS-defining cancers. ${ }^{4}$ In general, lung cancer patients living with HIV have a poor prognosis, with a life expectancy of 5 months in contrast with more than 12 months among non-HIV patients. ${ }^{5}$ Individuals living with HIV are considered to be too fragile for chemotherapy and have a poor bone marrow reserve; ${ }^{6}$ therefore, the benefit of cytotoxic chemotherapy is uncertain because these patients are excluded from clinical trials.

Epidermal growth factor receptor (EGFR)-tyrosine kinase inhibitors (TKIs), such as gefitinib and erlotinib, are promising targeted agents for lung cancer harboring EGFR mutations. The response rate to EGFR-TKIs in EGFR mutated lung cancer is $60 \%-80 \%$ and increases survival two-fold. ${ }^{7,8}$ The patient characteristics of those with lung cancer harboring EGFR mutations include being female, adenocarcinoma, non-smoker, and East Asian. ${ }^{9}$ Moreover, the frequency of mutated EGFR non-small cell lung cancers (NSCLCs) is 30\% in East Asian populations, ${ }^{10}$ whereas it is less than $10 \%$ in Western countries. ${ }^{11}$ Although the prevalence of EGFR mutations among the 
lung cancer patients living with HIV is uncertain, it will likely be greater than what is estimated because patients who have been reported to date are almost all from the United States and Europe. Also, individuals living with HIV are more likely to be smokers. ${ }^{12-14}$ Therefore, only one reported lung cancer patient living with HIV has been published previously. ${ }^{15}$

Herein, we present two lung cancer patients harboring EGFR mutations living with HIV and treated with EGFRTKIs.

\section{Case presentation Case I}

A 67 year old homosexual male patient treated with antiretroviral therapy for 3 years presented with locally advanced adenocarcinoma (stage IIIB) in the left lower lobe and synchronous early adenocarcinoma (stage IA) in the right upper lobe with different EGFR mutations (exon 19 E746-A750 del in the left lower lobe and exon 19 L747-S752 del in the right upper lobe). The category according to the United States Center for Disease Control and Prevention (CDC) Classification System for HIV was B2 (CD4 cell count 404 cells $/ \mu \mathrm{L}$ and viral load not detectable) and had a history of heavy cigarette smoking. The antiretroviral therapy included tenofovir/emtricitabine and raltegravir. First-line chemoradiotherapy maintained stable disease for 11 months; however, subsequent recurrence of liver and brain metastasis was evident (Figure 1A). The patient was treated with erlotinib and achieved a partial response (Figure 1B) for 9.7 months. Mild rash and anorexia occurred during treatment. After erlotinib failure, the patient underwent two lines of singlet chemotherapy (docetaxel and pemetrexed) and died 39.0 months after the lung cancer diagnosis.
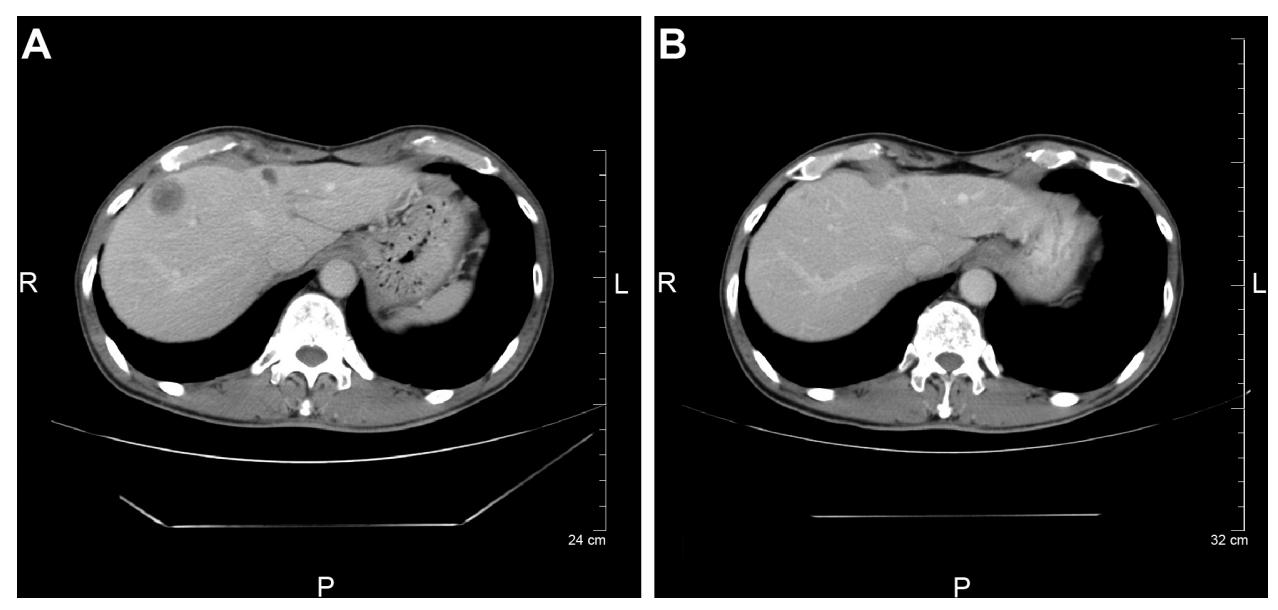

Figure I Computed tomography (CT) before and after treatment.

Notes: CT before treatment with erlotinib demonstrated hepatic metastasis $(\mathbf{A})$ and efficacy after 3 months of treatment (B).

\section{Case 2}

A 59 year old male patient underwent surgery for early lung cancer of T2aN0M0 before surgery and was diagnosed with T2aN2M0 stage IIIA pathologically. The patient underwent antiretroviral therapy (emtricitabine/tenofovir/darunavir) for 1 month before lung cancer was suspected. He was previously a light smoker. His CDC classification system for HIV was A3 (CD4 cell count 120 cells $/ \mu \mathrm{L}$ and viral load $2.1 \times 10^{4}$ copies $/ \mu \mathrm{L}$ ). His EGFR mutation status was exon 21 L858R. He was treated with adjuvant chemotherapy (cisplatin/ vinorelbine). His antiretroviral therapy was changed from danavir, a protease inhibitor, to raltegravir before adjuvant chemotherapy. He completed four subsequent cycles of chemotherapy; however, he suffered from disseminated varicella zoster during his last cycle. Six months later, recurrent left femoral bone metastasis with pathological fracture appeared; therefore, he underwent artificial femoral head replacement followed by radiotherapy to the femoral bone at a dose of $37.5 \mathrm{~Gy}$. However, 3 months later, multiple recurrences appeared in the left hip along the surgical scar (Figure 2A). He began treatment with gefitinib with poor performance status. A mild rash appeared, but he continued gefitinib treatment for 22.1 months (Figure 2B) until disease progression.

The clinical outcomes of the present cases are shown in Table 1 .

\section{Discussion}

The two patients living with HIV of recurrent NSCLC harboring mutated EGFR reported herein demonstrate the efficacy of EGFR-TKI treatment.

The number of HIV-infected patients with lung cancer has recently been increasing in the United States because of the 

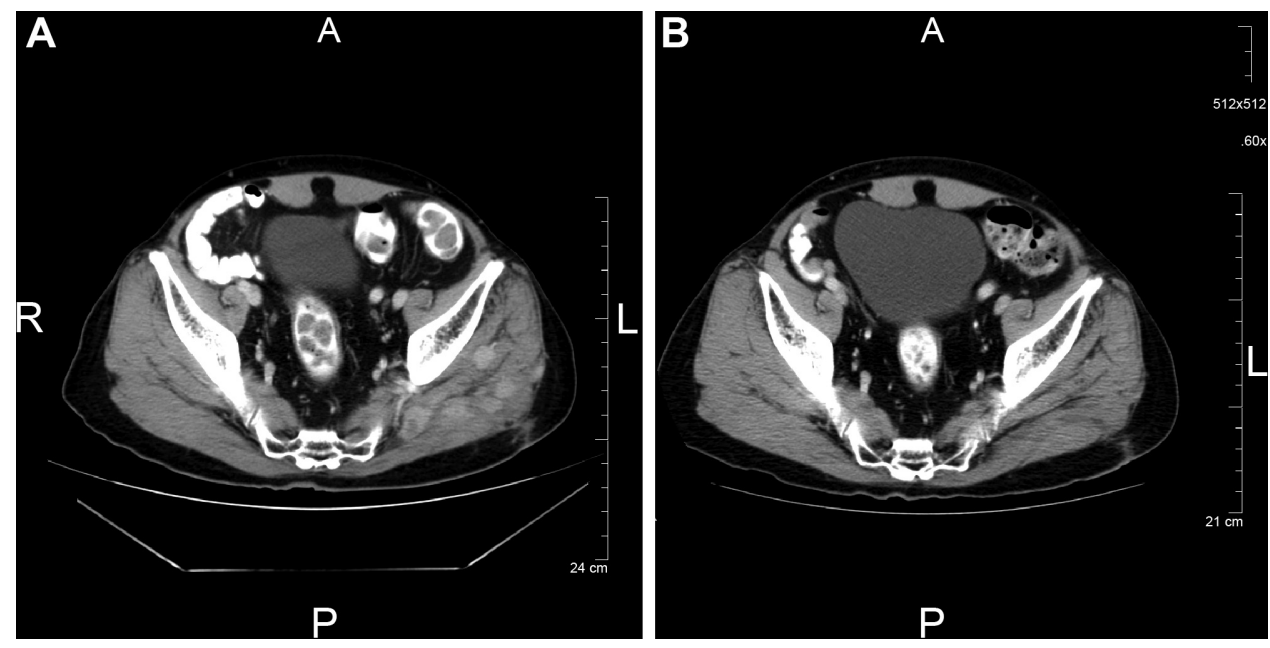

Figure 2 Multiple metastases in the hip muscle along the surgical incision.

Notes: (A) At the time of the recurrence. (B) Three months later, shrinkage was sustained for more than 19 months with gefitinib treatment.

change of disease spectrum from opportunistic infections to other diseases, a result of the introduction of antiretroviral therapy which strongly inhibits HIV and restores immunity of the patients. ${ }^{16,17}$ Lung cancer in HIV-infected patients is characterized by a younger age at onset, more rapid disease progression, and shorter survival compared to non-infected patients. ${ }^{5}$ There are several studies on the prognosis of HIVinfected patients with lung cancer treated with or without antiretroviral therapy, and the majority of studies conclude that there is additional benefit to concomitant therapy. ${ }^{18-20}$ Among advanced NSCLC patients with HIV infection having CD 4 cell counts greater than 200 cells $/ \mu \mathrm{L}, 75 \%-90 \%$ of reported patients benefited from standard chemotherapy and had a median survival of 11.5 months, a similar prognosis to that of advanced NSCLC patients without HIV infection. ${ }^{19}$ On the other hand, patients with a CD4 count less than 200 cells/ $\mu \mathrm{L}$ had a shorter median survival of 3.4 months. ${ }^{18}$

In the general population, the prognosis of advanced NSCLC has increased from two- to three-fold from 1995 to 2013. The treatment options are now diverse, and they have changed the strategy for treatment, especially with the discovery of driver oncogenes and molecular targeted treatment. Whether chemotherapy in HIV-infected patients with lung cancer is beneficial, and if so, details regarding the appropriate dose, remain unclear. Drug interactions between antiretroviral therapy and anticancer agents have been considered a possible issue, despite limited in vivo or in vitro data. ${ }^{21}$ In AIDS-associated lymphoma, ever since the advent of antiretroviral therapy, conventional-dose chemotherapy is recommended for patients with good performance status. Wang et al reported similar efficacies and toxicity profiles of CODOX-M/IVAC among patients with Burkitt's lymphoma with or without AIDS. ${ }^{22}$ Furthermore, the prognosis of patients treated with chemotherapy for Burkitt's lymphoma was similar to non-AIDS patients..$^{23,24}$ Further prospective investigations are required to determine whether the management of HIV patients with malignancies treated with chemotherapy is identical to non-HIV individuals. The standard treatment for lung cancer is evaluated and determined by clinical trials, but individuals living with HIV are excluded from these trials. Physicians should pay more attention to complications to avoid severe toxicities in these patients. Finally, the possibility of pharmacodynamic interactions or bone marrow fragility remains a concern due to the risk of myelosuppression caused by HIV. ${ }^{6}$ In fact, a recent Phase I/pharmacokinetic study of sunitinib with antiretroviral

Table I Summary of patients' characteristics including a reported case

\begin{tabular}{lllllllll}
\hline Author & Age & Sex & Stage & Histology & $\begin{array}{l}\text { Treatment } \\
\text { line }\end{array}$ & $\begin{array}{l}\text { EGFR } \\
\text { mutation }\end{array}$ & $\begin{array}{l}\text { Response } \\
\text { to EGFR-TKI }\end{array}$ & $\begin{array}{l}\text { Duration of response } \\
\text { (months) }\end{array}$ \\
\hline Erickson et al ${ }^{15}$ & 52 & F & IV & BAC (Adeno) & Ist-line & exon 19 & response & 14 \\
Present case I & 67 & M & rec & Adeno & 2nd-line & exon 19 & PR & 9.7 \\
Present case 2 & 59 & M & rec & Adeno & Ist-line & exon 21 & PR & 22.1 \\
\hline
\end{tabular}

Abbreviations: EGFR, epidermal growth factor receptor; EGFR-TKI, epidermal growth factor receptor-tyrosine kinase inhibitor; BAC, bronchioloalveolar carcinoma; Adeno, adenocarcinoma; rec, recurrence; PR, partial response. 
therapy for patients living with HIV demonstrated that a ritonavir (protease inhibitor)-based regimen required a reduced dose of sunitinib due to higher toxicities, whereas non-ritonavir-based regimens were more efficacious with standard sunitinib dosing. ${ }^{25}$

Advanced lung cancer cases with EGFR mutations treated with EGFR-TKIs are anticipated to have twice the survival than EGFR wild type patients. ${ }^{6,7}$ In East Asian females, nonor light-smoking patients, $30 \%-35 \%$ have EGFR mutations, while only $\sim 10 \%$ of all NSCLC cases in the Caucasian population were found to have EGFR mutations. ${ }^{11}$ Limited data demonstrating the rate of $E G F R$ mutation among lung cancer patients living with HIV was $35.7 \%$ in Japan. ${ }^{26}$ Therefore, a specific ethnic group; East Asian patients with concomitant HIV and lung cancer will require different clinical management and policies than Caucasian patients.

\section{Conclusion}

We report two lung cancer patients living with HIV and harboring EGFR mutations were active for EGFR-TKI with safety and long-term duration of response.

\section{Disclosure}

The authors have stated that they have no conflicts of interest.

\section{References}

1. Hammer SM, Squires KE, Hughes MD, et al. A controlled trial of two nucleoside analogues plus indinavir in persons with human immunodeficiency virus infection and CD 4 cell counts of 200 per cubic millimeter or less. AIDS Clinical Trials Group 320 Study Team. $N$ Engl J Med. 1997;337(11):725-733

2. Gulick RM, Mellors JW, Havlir D, et al. Treatment with indinavir, zidovudine, and lamivudine in adults with human immunodeficiency virus infection and prior antiretroviral therapy. $N$ Engl J Med. 1997;337(11):734-739.

3. Shiels MS, Pfeiffer RM, Gail MH, et al. Cancer burden in the HIVinfected population in the United States. J Natl Cancer Inst. 2011; 103(9):753-762.

4. Sepkowitz KA. AIDS - the first 20 years. N Engl J Med. 2001;344(23): 1764-1772.

5. Pakkala S, Ramalingam SS. Lung cancer in HIV-positive patients. J Thorac Oncol. 2010;5(11):1864-1871.

6. Sanchez X, Cousins-Hodges B, Aguilar T, et al. Activation of HIV-1 coreceptor (CXCR4) mediates myelosuppression. J Biol Chem. 1997;272(44):27529-27531.

7. Mitsudomi T, Morita S, Yatabe Y, et al. Gefitinib versus cisplatin plus docetaxel in patients with non-small-cell lung cancer harbouring mutations of the epidermal growth factor receptor (WJTOG3405): an open label, randomised phase 3 trial. Lancet Oncol. 2010;11(2):121-128.

8. Maemondo M, Inoue A, Kobayashi K, et al. Gefitinib or chemotherapy for non-small-cell lung cancer with mutated EGFR. $N$ Engl J Med. 2010;362:2380-2388.

9. Shepherd FA, Rodrigues Pereira J, Ciuleanu T, et al. Erlotinib in previously treated non-small-cell lung cancer. $N$ Engl J Med. 2005; 353(2):123-132.
10. Shah NT, Kris MG, Pao W, et al. Practical management of patients with non-small-cell lung cancer treated with gefitinib. J Clin Oncol. 2005;23(1):165-174.

11. Rosell R, Moran T, Queralt C, et al. Screening for epidermal growth factor receptor mutations in lung cancer. $N$ Engl $J$ Med. 2009;361(10):958-967.

12. Burns DN, Hillman D, Neaton JD, et al. Cigarette smoking, bacterial pneumonia, and other clinical outcomes in HIV-1 infection. Terry Beirn Community Programs for Clinical Research on AIDS. J Acquir Immune Defic Syndr Hum Retrovirol. 1996;13(4):374-383.

13. Niaura R, Shadel WG, Morrow K, et al. Human immunodeficiency virus infection, AIDS, and smoking cessation: the time is now. Clin Infect Dis. 2000;31(3):808-812.

14. Hughes JR. Treatment of smoking cessation in smokers with past alcohol/drug problems. J Subst Abuse Treat. 1993;10(2):181-187.

15. Erickson TM, Koeppe JR, Miller YE, Stuart RW, Camidge DR. Bronchioloalveolar carcinoma presenting as chronic progressive pulmonary infiltrates in a woman with HIV: a diagnosis worth making. $J$ Thorac Oncol. 2008;3(11):1353-1355.

16. Engels EA, Pfeiffer RM, Goedert JJ, et al. Trends in cancer risk among people with AIDS in the United States 1980-2002. AIDS. 2006;20(12):1645-1654.

17. Herida M, Mary-Krause M, Kaphan R, et al. Incidence of non-AIDSdefining cancers before and during the highly active antiretroviral therapy era in a cohort of human immunodeficiency virus-infected patients. J Clin Oncol. 2003;21(18):3447-3453.

18. Hakimian R, Fang H, Thomas L, et al. Lung cancer in HIV-infected patients in the era of highly active antiretroviral therapy. $J$ Thorac Oncol. 2007;2(4):268-272.

19. Lavole A, Chouaid C, Baudrin L, et al. Effect of highly active antiretroviral therapy on survival of HIV infected patients with non-small-cell lung cancer. Lung Cancer. 2009;65(3):345-350.

20. Hooker CM, Meguid RA, Hulbert A, et al. Human immunodeficiency virus infection as a prognostic factor in surgical patients with non-small cell lung cancer. Ann Thorac Surg. 2012;93(2):405-412.

21. Makinson A, Pujol JL, Le Moing V, Peyriere H, Reynes J. Interactions between cytotoxic chemotherapy and antiretroviral treatment in human immunodeficiency virus-infected patients with lung cancer. $J$ Thorac Oncol. 2010;5(4):562-571.

22. Wang ES, Straus DJ, Teruya-Feldstein J, et al. Intensive chemotherapy with cyclophosphamide, doxorubicin, high-dose methotrexate/ ifosfamide, etoposide, and high-dose cytarabine (CODOX-M/IVAC) for human immunodeficiency virus-associated Burkitt lymphoma. Cancer. 2003;98(6):1196-1205.

23. Oriol A, Ribera JM, Esteve J, et al. Lack of influence of human immunodeficiency virus infection status in the response to therapy and survival of adult patients with mature B-cell lymphoma or leukemia. Results of the PETHEMA-LAL3/97 study. Haematologica. 2003;88(4):445-453.

24. Galicier L, Fieschi C, Borie R, et al. Intensive chemotherapy regimen (LMB86) for St Jude stage IV AIDS-related Burkitt lymphoma/ leukemia: a prospective study. Blood. 2007;110(8):2846-2854.

25. Rudek MA, Moore PC, Mitsuyasu RT, et al. A phase 1/pharmacokinetic study of sunitinib in combination with highly active antiretroviral therapy in human immunodeficiency virus-positive patients with cancer: AIDS Malignancy Consortium trial AMC 061. Cancer. 2014;120(8): 1194-1202.

26. Okuma Y, Tanuma J, Otera H, et al. 1567PA multi-institutional surveillance of clinicopathological features and molecular epidemiology of egfr mutations in lung cancer patients living with human immunodeficiency virus infection in Japan. Annals of Oncology. 2014;25(Suppl 4): iv545. 


\section{Publish your work in this journal}

OncoTargets and Therapy is an international, peer-reviewed, open access journal focusing on the pathological basis of all cancers, potential targets for therapy and treatment protocols employed to improve the management of cancer patients. The journal also focuses on the impact of management programs and new therapeutic agents and protocols on
Dovepress

patient perspectives such as quality of life, adherence and satisfaction. The manuscript management system is completely online and includes a very quick and fair peer-review system, which is all easy to use. Visit http://www.dovepress.com/testimonials.php to read real quotes from published authors.

Submit your manuscript here: http://www.dovepress.com/oncotargets-and-therapy-journal 